\title{
Discursos Selvagens-Disciplinados: Os Saberes Psis na Arqueologia de Foucault ${ }^{1}$
}

\author{
Fernando de Almeida Silveira ${ }^{2}$ \\ Universidade Federal de São Paulo (Campus Baixada Santista) \\ Richard Theisen Simanke \\ Universidade Federal de São Carlos
}

\begin{abstract}
RESUMO - Michel Foucault investiga a diversidade dos sistemas e o jogo das descontinuidades na história dos discursos do senso comum, pré-científicos e científicos, dentre eles, o da psicologia. Esta pesquisa estuda a ordem do discurso foucaultiano sobre a psicologia nas seguintes obras desse autor: Sobre a Arqueologia das Ciências - Resposta ao Círculo Epistemológico, A Arqueologia do Saber e A Ordem do Discurso. Verificou-se que Foucault critica a pressuposição de uma história contínua, unitária e totalizadora da psicologia, já que pluralizada, em seu processo de constituição, pelos múltiplos jogos de verdades da história dos discursos. Conclui-se que Foucault evidencia o apagamento dos contornos do campo discursivo da psicologia, como dos demais discursos da história do pensamento humano, de maneira inter-relacionada.
\end{abstract}

Palavras-chave: Foucault; Psicologia; saberes psis; discurso.

\section{Wild-Disciplined Speechs: The Psis Knowledges in the Foucault's Archaelogy}

\begin{abstract}
Michel Foucault describes the diversity of systems and the set of discontinuities in the history of common sense discourses, pre-scientific and scientific, among them that of psychology. This research studies the order of Foucaut's discourse about psychology in the following works: About the Archeology of Sciences-An Answer to the Epistemological Circle, The Archeology of Knowledge and The Order of Discourse. It was verified that Foucault criticizes the assumption of a continuous, unitary and totalizing history of psychology and argues that in its developmental process, psychology was pluralized by multiple truth sets of the history of discourses. It was concluded that Foucault highlights the whiteout of the boundaries in psychology's discursive field, as well as in other discourses in the history of human thought, in an interrelated way.
\end{abstract}

Keywords: Foucault; Psychology; psis knowledge; speech.

Em seu artigo Resposta a Uma Questão (1968/1972), ao discorrer sobre as características dos seus estudos acerca da produção dos discursos na história do pensamento ocidental desenvolvidos, com destaque, na década de 1960 -, Foucault vem compor, com as investigações desse artigo, as questões discursivas apresentadas em livros tais como História da Loucura (1961) e As Palavras e as Coisas (1966), esclarecendo que seu trabalho de todo esse período, no seu efeito de conjunto, é uma tentativa de introduzir "a diversidade dos sistemas e o jogo das descontinuidades na história dos discursos" (p. 67).

1 Este trabalho se originou de uma parte do projeto de pós-doutorado do primeiro autor, em 2008, desenvolvido no Departamento de Filosofia e Metodologia das Ciências da Universidade Federal de São Carlos. Meus agradecimentos à FAPESP pelo financiamento desse projeto $\mathrm{e}$ aos professores Richard Simanke e Étienne Bimbenet, supervisores do projeto no Brasil (Filosofia - UFSCar) e na França (Filosofia -Universidade de Lyon), respectivamente.

2 Endereço para correspondência: Departamento de Saúde, Educação e Sociedade. Universidade Federal de São Paulo, Campus Baixada Santista. Avenida D. Ana Costa, 95, $1^{\circ}$. Andar, Vila Mathias. Santos, SP. CEP 11060-001.E-mail: fernandos.unifesp@gmail.com.
Para tanto, Foucault intenciona investigar a pluralidade dos sistemas de discursos do senso comum, dos saberes pré-científicos e da ciência propriamente dita, em suas evoluções descontínuas e imbricações multifacetadas, em uma abordagem arqueológica complexa. Essa abordagem não só investiga a individualização de cada discurso, saber ou ciência historicamente situado, mas busca, segundo o próprio Foucault (1968/1972), um estudo "mais enigmático" (p. 58), conforme os exemplos a seguir:

Quando se fala da psiquiatria, ou da medicina, da gramática, da biologia, ou da economia, de que se fala? Que são estas curiosas unidades que se acredita poder reconhecer ao primeiro olhar, mas em relação às quais ficaríamos bem embaraçados para definir os limites? Unidades entre as quais algumas parecem remontar ao fundo de nossa história (a medicina não menos que as matemáticas), enquanto que outras apareceram recentemente (a economia, a psiquiatria), e outras, talvez, desapareceram (a casuística). Unidades onde vêm se inscrever indefinidamente enunciados novos e que se encontram sempre modificadas por eles (estranha unidade da sociologia ou da psicologia que desde seu nascimento não pararam de recomeçar) (Foucault, 1968/1972, p. 58). 
Em outras palavras, compreendemos que o que está em jogo na questão das formações dos discursos para Foucault é a sua suspeita que questiona a emergência histórica de cada unidade discursiva enquanto um sistema de saber fechado e naturalizadamente evidente. Em contrapartida, passa, então, a analisar esses discursos em seus jogos de produção enviesados e, muitas vezes, mutuamente inter-relacionados e só discerníveis a partir da pesquisa de amplos momentos históricos, muitas vezes de difícil elucidação global pelo sujeito cognoscente, em determinado "aqui-agora" da história da humanidade.

Nas palavras de Foucault, "eu estudei, cada um a sua vez, conjuntos de discursos; eu os caracterizei; eu defini jogos de regras, transformações, limiares, mudanças; eu os compus entre si, eu descrevi feixes de relações" (1968/1972, p. 61).

Aliás, é importante ressaltar que, para Foucault (1968/1972), a constituição dos referidos feixes de relações entre os variados discursos de determinada época pressupõe a compreensão que a sua decorrente epistemologia não seja como a "soma de seus conhecimentos, ou estilo geral de pesquisas, mas o afastamento, as distâncias, as oposições, as diferenças, as relações de seus múltiplos discursos científicos" (p. 60). Dessa forma, a epistemologia de uma época não é nem "a soma de seus conhecimentos, ou o estilo geral de suas pesquisas" (p. 60), nem uma "espécie de grande teoria subjacente" (p. 60) ou a grande e única história contínua das ciências, mas sim "um espaço de dispersão, é um campo aberto e, sem dúvida, indefinidamente descritível de relações" (p. 60), no qual a psicologia ocupa seu espaço com historicidade própria, em constante mutação.

Por sua vez, é possível reconhecer, dentre a diversidade de saberes estudados por Foucault, a psicologia como uma das singulares unidades de discursos historicamente situados e que demandam um estudo atento para o reconhecimento de sua específica individualização, conforme propomos realizar por meio deste trabalho sobre Foucault.

\section{Método}

Neste artigo, estudaremos a noção de psicologia na arqueologia de Foucault, tendo como foco a leitura e análise interpretativa do importante texto, Sobre a Arqueologia das Ciências - Resposta ao Círculo Epistemológico (1968), seguida da análise do saber psicológico no seu livro Arqueologia do Saber (1969), até sua célebre aula inaugural de ingresso no Collège de France, A Ordem do Discurso (1971), representativa de uma fase do trabalho de Foucault na qual os princípios de sua arqueologia são explicitados em correlação aos fundamentos de sua fase genealógica emergente. Partiremos do escrito de Foucault cronologicamente mais 'atual', A Ordem do Discurso, prosseguindo sucessivamente deste texto mais 'recente', sucedido pelos outros dois, do mais recente ao mais antigo.

\section{Resultados}

\section{A ordem do discurso psicológico}

Na sua aula inaugural de ingresso no Collège de France, intitulada A Ordem do Discurso, Foucault (1971/1996) discorre sobre a arqueogenealogia dos discursos, destacando tanto os pressupostos fundantes da produção dos saberes em geral, como sinalizando os princípios norteadores tanto de sua arqueologia como de sua genealogia, em suas articulações recíprocas.

O caráter amplo dessa análise dos sistemas de dispersão e rarefação dos discursos dá visibilidade a amplos campos enunciativos, nos quais os saberes psicológicos podem também emergir e serem constituídos.

Foucault (1971/1996) parte da hipótese de que a produção do discurso é, "ao mesmo tempo, controlada, selecionada, organizada e redistribuída" (p. 9) por procedimentos que teriam como função "conjurar seus poderes e perigos, dominar seu acontecimento aleatório, esquivar sua pesada e temível materialidade" (p. 9).

Ora, o que está em jogo é a própria contenção do caráter difuso do acontecimento discursivo em sua expressividade rarefeita e fragmentada e, portanto, perigosa, devido a esse caráter descontínuo e fortuito de sua dizibilidade. É o que Foucault nos aponta ao considerar a existência de procedimentos de exclusão do acontecimento discursivo, a partir de três configurações.

A primeira delas, denominada por Foucault (1971/1996) de procedimento de interdição (p. 9), refere-se ao fato de que não se é permitido, em determinada sociedade, dizer tudo a respeito de qualquer coisa ou em qualquer circunstância. Esse procedimento pode ser dividido em três sub-ramificações, referentes tanto ao "tabu do objeto", como ao "ritual da circunstância" ou ao "direito privilegiado ou exclusivo do sujeito que fala" (p. 9), às quais poderiam se inter-remeter na constituição da exclusão do acontecimento discursivo.

Ao citar como exemplo os discursos da sexualidade e da política enquanto suscetíveis de interdição, Foucault nos desperta a reflexão de que a pretexto de se submeter corpos e almas a potenciais zonas de silêncio e de mutismo, o que está em jogo é a multiplicação incessante de discursos sobre tais referidos temas-tabus.

Em decorrência, tem-se a renovada fixação e identificação do sujeito psicológico a tais temáticas, em virtude da produção de múltiplos discursos sobre as questões da interdição. Ou seja, se no interior do discurso dos interditos os temas são da submissão dos sujeitos ao silêncio e ao mutismo, o que se tem, do ponto de vista arqueológico, é a multiplicação de discursos e de renovados campos de verdades enquanto característica principal desse procedimento.

Aliás, essa produção intensa de dizeres, muitos deles sobre a psicologia do sujeito, no transcurso da história da humanidade, é o que também poderíamos supor ocorrer quanto aos discursos sobre o louco. No entanto, esses não 
são apenas interditáveis, mas principalmente suscetíveis ao segundo procedimento de exclusão: a separação e a rejeição.

Isto nos remonta ao fato de que, desde a Alta Idade Média, o discurso do louco é o que circula à parte do discurso dos outros indivíduos. Sua palavra é anulada, o que o torna um incapaz jurídico e o exclui, inclusive naquele período, do ritual religioso da comunhão.

Palavra nula, não ouvida nem registrada, é contraditoriamente material para configuração de formações discursivas que irão, em poucos séculos - conforme Foucault desenvolve ao abordar a psicologia na História da Loucura (1961/1994) -, promover as condições discursivas para a constituição da prática social do internamento do louco ou da identificação da sua conduta ao redor do conceito de doença mental.

Esse deslocamento permitirá o desenvolvimento de uma psicologia que acessa o discurso da loucura e o inventa, distinguindo-o dos discursos dos sensatos e dos normais e delimitando os dizeres dele à ordem cientificamente concebida dos discursos da desrazão, em seus decorrentes efeitos produtores de verdades e práticas de exclusão.

O que se verifica, dissociando-nos da temática específica da loucura, é a própria questão da constituição dos jogos do que seja verdadeiro ou falso na contraditória configuração do surgimento, principalmente a partir da Modernidade, do homem como sujeito e objeto de conhecimento.

A esse respeito, em $A$ Ordem do Discurso, Foucault (1971/1996) destaca que esse terceiro procedimento de exclusão, a partir da delimitação do que seja verdadeiro ou falso nos discursos, fora mais estimulado a partir dos séculos XVI e XVII na Inglaterra, por meio da intensificação das formações discursivas que se voltavam para a incitação da vontade de saber do sujeito cognoscente, com o desenvolvimento da ciência positivista moderna.

Esses discursos da vontade de saber se abriam à invenção de uma série de práticas e técnicas, as quais permitiram, ao cientista, seu posicionamento social na produção da verdade. Se, nessa formação discursiva, uma rede múltipla de instituições se fazia presente - sistemas de livros, edições, bibliotecas, sociedades de sábios (que seriam a base dos atuais laboratórios) -, todo esse enredamento de práticas discursivas possibilitou, nas palavras de Foucault (1971/1996), a “história dos planos de objetos a conhecer, a história das funções e posições do sujeito cognoscente, história dos investimentos materiais, técnicos, instrumentais do conhecimento" (p. 17).

É no espaço enunciativo da articulação desses três grandes sistemas de exclusão que atingem o discurso - a palavra proibida, a segregação da loucura e a vontade de verdade - que veríamos emergir, no interstício de suas produções, o desejo e o poder na constituição dos saberes modernos.

É o que compreendemos ocorrer na medida em que a distribuição institucional dessas práticas discursivas nas faculdades, hospitais, laboratórios, nas clínicas de psicologia, indústrias, enfim, nas famílias e em seus lares, aliadas a interesses econômicos, políticos, morais, éticos e sociais, promoveria a produção de sujeitos acessados a toda uma reconfiguração histórico-científica, no desenvolvimento, renovado ou inédito, de vários ramos de conhecimento, dentre eles, o Direito, a Medicina, a Sociologia, a Antropologia, a História e a Linguística.
Especial destaque é dado aos saberes psi (a psicologia, a psiquiatria, a psicanálise), os quais, principalmente a partir do século XIX.

Segundo Foucault, esses saberes psis dariam sustentação a um processo de medicalização, de normalização e produção, não só de um sujeito jurídico apenável pelos magistrados mas, por meio de seus laudos periciais, de toda uma invenção da identidade do sujeito moderno.

Nesse sentido, é possível encontrar, no contexto geral de toda a obra de Foucault, uma série de figuras identitárias do sujeito moderno enquanto produto central do exercício dos saberes psicológicos. Dentre tais figuras identitárias, podemos nos referir, ilustrativamente, às figuras do indivíduo delinquente, anormal, perverso, detentor de uma fisionomia rígida de sexualidade, antissocial, sexualmente patológico, hospitalizável, periculoso, internável nos hospícios, dentre outras possibilidades de constituição de sujeitos produzidos no transcurso da história dos saberes psi.

É sob esse prisma que Foucault (1971/1996) ressalta um aspecto pertinente às ciências em geral, $(\mathrm{e}$, portanto, aos saberes psicológicos), no que diz respeito à constituição de uma disciplina. Para ele, a disciplina "não é a soma de tudo o que pode ser dito de verdadeiro sobre alguma coisa; não é nem mesmo o conjunto de tudo o que pode ser aceito, a propósito de um mesmo dado, em virtude de um princípio de coerência ou de sistematicidade" (p. 31). Isso é exemplificado ao apontar que "a medicina não é constituída de tudo o que se pode dizer de verdade sobre a doença; a botânica não pode ser definida pela soma de todas as verdades que concernem às plantas" (p. 31).

Nesse contexto, o que seria importante ressaltar é o fato de que as disciplinas são feitas de erros e de verdades e que ambos teriam uma função positiva na dinâmica histórica de cada disciplina, ou seja, a própria possibilidade de reconhecer um enunciado como verdadeiro ou falso só ocorreria na medida em que, preliminarmente, pudéssemos situá-lo de acordo com as condições de possibilidade de determinada disciplina, sempre em constante atualização e em relação às variações dos rearranjos que emergem na história desses saberes.

Assim, antes que um enunciado diga a verdade ou a falsidade sobre certo objeto da ciência, faz-se necessário que ela se situe no verdadeiro, ou seja, no limite dos jogos de identidade, inerente às regras de determinado saber, visando à construção de novos enunciados, ou na formulação de proposições novas sobre um objeto de disciplina.

Isso nos leva a considerar a constituição histórica e provisoriamente situada dos saberes psicológicos. $\mathrm{Na}$ medida em que a verdade do sujeito psicológico é inventada nos embates dos discursos dos seus respectivos saberes psi, essa característica de invenção do sujeito psicológico por meio desses referidos embates discursivos relativiza o próprio estatuto do que venha a ser tal veracidade, tanto do sujeito em si como do próprio saber que o constitui.

$\mathrm{Na}$ medida em que os próprios fundamentos dos discursos psicológicos estão em constante mutação e atualização e em revisão incessante de suas regras, o que se tem é que a disciplina, no geral, é um espaço e um "princípio de controle da produção dos discursos” (Foucault, 1971/1996, p. 36). 
Daí, advindo seu poder de "polícia", restritivo e coercitivo, pois situar nossos dizeres no contexto do historicamente verdadeiro de uma disciplina é submetê-los às referidas regras que determinam a própria constituição de existência de uma disciplina específica.

Essa inserção dos discursos no verdadeiro de uma disciplina criaria duas instâncias: aquela referente às proposições cientificamente reconhecidas como verdadeiras e falsas - e, portanto, inseridas no contexto de uma disciplina - e aquela referente aos dizeres que habitariam o espaço discursivo de exterioridade ao conteúdo disciplinar - ou seja, enunciados da sua borda, afeitos ao que Foucault (1971/1996) denominou de "teratologia do saber" enquanto "quimera", "divagação" marginal, "monstruosidade linguística", que tanto podem se remeter à experiência imediata ou a temas imaginários que reconduzem a crenças sem memória (p. 33).

O importante, segundo Foucault (1971/1996), é reconhecer a inexistência estrita do erro, pois a própria concepção de erro só emergiria de uma prática definida, determinadora do que esteja no âmbito do verdadeiro e do que seja exterioridade monstruosa à disciplina. Dessa maneira, desnaturaliza-se o caráter verdadeiro ou falso de um discurso científico e se constata os jogos históricos de verdades, que o legitima como tal.

Isso nos lança à própria fundamentação do que seja a arqueologia de Foucault. Na medida em que Foucault (1971/1996) questiona os próprios pressupostos de nossa vontade de verdade, temos o surgimento de uma análise do que seja o discurso enquanto elemento de produção de campos de verdade (no interior de suas práticas constitutivas); como também em sua decorrente função de produção do que Foucault denominou de "exterioridade selvagem" (p. 35) ao seu campo de delimitação: efeito da 'polícia' discursiva inerente à sua referida função de inclusão no verdadeiro das disciplinas e a consequente produção de exterioridades de discursos 'monstruosos' e a ela marginais.

Assim, a emergência de múltiplos campos discursivos, sob a forma cristalizadora (mas mutável) de variadas disciplinas criaria uma topologia descontínua de discursos, sejam eles incluídos ou excluídos dos conteúdos disciplinares, na edificação do pensamento ocidental.

A essa delimitação do acontecimento discursivo em séries disciplinares, à investigação da regularidade de seus deslocamentos, bem como à verificação das condições de possibilidade de suas manifestações, está relacionada a análise arqueológica, neste texto, denominada de análise do "conjunto crítico", que visa "procurar cercar as formas da exclusão, da limitação, da apropriação [do acontecimento discursivo] (...); mostrar como se formaram, para responder a que necessidades, como se modificaram e se deslocaram, que força exerceram efetivamente, em que medida foram contornadas" (Foucault, 1971/1996, p. 60). Sendo assim, esse conjunto crítico analisa "os sistemas de recobrimento do discurso", ao detectar "princípios de ordenamento, de exclusão, de rarefação do discurso (p. 69).

$\mathrm{Se}$, em estudos futuros, a análise genealógica será reconhecida enquanto "um diagnóstico que se concentra nas relações de poder, saber e corpo na sociedade moderna" (Dreyfus \& Rabinow, 1984/1995, p. 117), nessa aula inaugural ela aparece como a investigação da "formação efetiva do discurso" enquanto "poder de constituir domínios de objetos, a propósito dos quais se poderiam afirmar ou negar proposições verdadeiras ou falsas" (Foucault, 1971/1996, pp. 69-70) na análise da formação de "sistemas de coerção", da sua "norma específica" (pp. 69-70) e de suas condições de aparição, crescimento e variação.

Assim, estaríamos diante de duas análises inseparáveis e que se remetem mutuamente: a análise das articulações entre acontecimento discursivo e sua apropriação ou exclusão pelas disciplinas e dos processos de poder inerentes a tais práticas discursivas na constituição de seus objetos, parâmetros de normalidade e seus inerentes sistemas de coerção.

Mais especificamente, para Foucault (1971/1996), o entrecruzamento de múltiplas séries de discursos permite circunscrever o lugar, a contingência e a aparição do acontecimento discursivo e das disciplinas, dentre elas, conforme ressaltamos, a psicologia, como também os processos rituais de definição de seu objeto de estudo e de legitimação do poder de proferir suas verdades, os quais reconhecemos, por meio da figura socialmente estabelecida e reconhecida do psicólogo, psiquiatra ou psicanalista enquanto indivíduo capacitado para o exercício e atualização desse campo específico de verdades. Ou seja, segundo compreendemos, o profissional do saber psi não como o detentor do conhecimento verdadeiro, mas como o indivíduo inserido, por meio de rituais discursivos, no verdadeiro dos saberes psis em constante mutação.

\section{A arqueologia do saber psicológico}

O referido processo de delimitação do acontecimento discursivo, como vimos, dá margem ao surgimento de enunciados contidos no interior e no exterior de uma determinada disciplina. Para Foucault, (1969/1997) o objetivo de uma arqueologia dos saberes se destinaria a uma "descrição dos acontecimentos discursivos como a busca das unidades que aí se formam" (p. 30), sejam elas científicas ou não, visto que o processo de produção de enunciados (sejam eles falados ou escritos) gera multiplicidades de campos de acontecimentos discursivos no transcurso da história da humanidade, das mais diversas categorias.

Aliás, os domínios de intervenção e atuação desses acontecimentos discursivos são variados e relativos à sua posição na topologia dos demais acontecimentos discursivos inerentes a uma determinada época e sociedade. Ou seja, mais do que tipificar um discurso enquanto texto político, romance, diagnose psiquiátrica, doutrina religiosa, jurisprudência jurídica, por exemplo, o que se busca verificar é a topologia na qual ele se situa na produção dos saberes, dentre eles os científicos, como uma de suas possíveis, mas não única possibilidade.

Assim sendo, em Arqueologia do Saber, Foucault (1969/1997) analisará os diferentes limiares discursivos que permitem a transformação de um acontecimento discursivo em um saber (sejam eles científicos ou não), dentre eles, os saberes psis. Isso sem perder de vista que, em uma sociedade, em determinado momento histórico coexistem multiplicidades de discursos, conforme acabamos de exemplificar.

Por sua vez, Foucault (1969/1997) reconhece que a disciplina é uma das formas mais bem acabadas e definidas 
de discurso científico, pois é o "conjunto de enunciados que toma emprestado de modelos científicos sua organização, que tendem à coerência e à demonstratividade, que são recebidos, institucionalizados, transmitidos e ensinados como ciências" (pp. 201/202). No que se refere à ciência, Foucault ressalta que um saber científico nunca contém completamente as formações discursivas a partir das quais ele se edifica.

Exemplificativamente, compreendemos que são formações discursivas referentes ao saber psicológico: textos literários, artigos jurídicos, tratados filosóficos, disposições políticas, laudos periciais, preceitos religiosos, opiniões do senso comum, um non-sense esquizofrênico, dentre outros. Assim, um romance de cunho psicológico, mesmo não inscrito enquanto ciência psicológica, a ela se remete enquanto acontecimento discursivo formador do saber psicológico.

Temos aí, uma distinção fundante na arqueologia de Foucault: a de que nem todo saber é ciência, nem mesmo conhecimento e de que distinguir tais limiares é central para situarmos, com especial destaque, a psicologia enquanto campo de saber pretensamente científico.

Neste sentido, Foucault (1969/1997) define que saber "é o domínio constituído pelos diferentes objetos que irão adquirir ou não um status científico" (p. 206). Como exemplo, destacamos que os estudos da alma humana podem dar espaço à constituição de um saber religioso, de dizeres psicanalíticos ou de uma prática discursiva behaviorista.

Além dessa definição, o saber é compreendido como "o espaço em que o sujeito pode tomar posição para falar dos objetos de que se ocupa em seu discurso" (Foucault, 1969/1997, p. 206). Assim, segundo nossa reflexão, teríamos que o saber xamânico permite, ao feiticeiro da tribo, o exercício de uma posição nos discursos espirituais de sua comunidade, em uma topologia de verdades distinta daquela do filósofo grego, no período socrático, ou do psicólogo em um departamento de recursos humanos, no começo do século XXI.

É também o campo de coordenação e de subordinação dos enunciados em que os conceitos aparecem, se definem, se aplicam e se transformam. Por exemplo, reconhecemos que, atualmente, existem deslocamentos entre o que seja saber científico ou pré-científico, como no caso das denominadas terapias alternativas perante a psicologia. Ou como no contexto do Conselho de Psicologia brasileiro que reconhece a Acupuntura como técnica psicológica, em confronto com os limites de atuação estabelecidos pelos ditames da medicina ou de outras profissões.

Finalmente, "um saber se define por possibilidades de utilização e de apropriação oferecidas pelo discurso" (Foucault, 1969/1997, p. 206). Por exemplo, o campo de atuação de um psicólogo em um contexto histórico no qual o manicômio era discursivamente legitimado como um espaço adequado para a sua atuação profissional será diverso no contexto histórico no qual, hipoteticamente, o discurso anti-manicomial vai redispor os enunciados e a maneira de atuação do referido profissional.

Nesse âmbito, Foucault (1969/1997) destaca que "há saberes que são independentes das ciências, mas não há saber sem uma prática discursiva definida, e toda prática discursiva pode definir-se pelo saber que ela forma" (p. 207), de modo que um conjunto de práticas discursivas delimita um campo de saber específico, científico ou não.
A partir dessa distinção básica entre saber e ciência, é possível nos voltarmos para os patamares discursivos inerentes ao contexto de formação científica.

O primeiro limiar, o da positividade, é definido por Foucault (1969/1997) como "o momento a partir do qual uma prática discursiva se individualiza e assume sua autonomia; o momento, por conseguinte, em que se encontra em ação um único e mesmo sistema de formação de enunciados, ou, ainda, o momento em que esse sistema se transforma" (p. 211).

Ilustrando o nosso trabalho, ressaltamos que a alma é conceito-chave para um conjunto variado de práticas discursivas, as quais, por sua vez, vão se individualizando, considerando que podem se remeter, diferentemente, conforme exemplificamos, a estudos astrológicos, ao contexto da neurologia ou ao âmbito da psicologia.

Será o limiar posterior que irá garantir a transmutação dessa positividade em epistemologização. Essa transmutação ocorre pela emergência de certo conjunto de enunciados, os quais passarão a constituir uma formação discursiva, no sentido de definir "normas de verificação e de coerência e o fato de que [este conjunto de enunciados] exerce em relação ao saber uma função dominante (modelo, crítica ou verificação)" (Foucault, 1969/1997, p. 211). É assim que compreendemos, por exemplo, que o conjunto de enunciados da astrologia chinesa, originariamente usado para definição dos períodos de plantio e de colheita, foi se desgarrando dos elementos de sua formação discursiva que remontavam à agricultura, para se configurar como uma análise simbólica da personalidade humana. Ou como também ilustramos que é o caso das práticas discursivas de Charcot sobre a histeria feminina, no século XIX, que se remetiam ao contexto psiquiátrico, por meio do instrumental da hipnose, para serem reapropriadas como um dos elementos de definição epistêmica da Psicanálise por Freud, na definição de conceitos como transferência ou de manifestação inconsciente.

Em ambos os casos acima, o que verificamos é a configuração de dois campos de saberes. O primeiro, norteado pelos enunciados de um período pré-científico da Antiguidade chinesa, no qual o reconhecimento das leis de semelhança entre o microcosmo e o macrocosmo já era suficiente para a determinação de um campo de saber astrológico. $\mathrm{O}$ segundo - psicanalítico -, emergente do pensamento moderno, que também busca a definição dos critérios de formação de seus discursos.

Sob esta ótica, destacamos a diferença, que visamos reconhecer, de que a atmosfera científica na qual a Psicanálise emerge a predispõe a uma maior consolidação de seus enunciados a certas leis de construção de proposições de cientificidade. Esse reconhecimento se justifica no sentido de apresentarmos o que Foucault denomina de terceiro limiar - o da cientificidade -, em sequência ao processo de elaboração discursiva, referentes aos outros dois limiares, já aqui estudados: de positividade e de epistemologização.

Aliás, consideramos que a insistência de Freud de que a Psicanálise não se reduzisse a uma relação analítica, mas preenchesse os requisitos mínimos desse limiar da cientificidade (Monzani, 1989, p. 21), assemelha-se, em certo grau, ao esforço dos psicólogos de distanciarem seu objeto de estudo dos enunciados filosóficos da alma, com o intuito de situá-lo no contexto das positividades científicas. 
Como ápice dessa configuração científica, teríamos o quarto limiar, o de formalização, o qual, segundo Foucault (1969/1997), ocorre quando um discurso científico "puder definir os axiomas que lhe são necessários, os elementos que usa, as estruturas proposicionais que lhe são legítimas e as transformações que aceita, quando puder assim desenvolver, a partir de si mesmo, o edifício formal que se constitui" ( $p$. 211).

Como exemplo de formalização de uma ciência, Foucault (1969/1997) aponta a matemática enquanto unidade discursiva que se legitima sobre a sua própria historicidade, já que é ciência que "retranscreve seu percurso histórico real, no vocabulário das vizinhanças, das dependências, das subordinações, das formalizações progressivas, das generalidades que se enredam" (p. 215) na inter-relação de todos os seus teoremas, hipóteses e produções científicas. De maneira que cada proposição algébrica é ingenuamente apresentada, purificada de seu contexto de produção histórica, já que universalizada como verdade atemporal. A esse respeito, retomaremos com detalhes ao analisarmos as diferenças de formalização da psicologia e da matemática, no contexto do artigo Sobre a Arqueologia das Ciências - Resposta ao Círculo Epistemológico.

Foucault (1969/1997), então, define, nessa obra, epistemologia como "o conjunto das relações que podem unir, em uma dada época, as práticas discursivas que dão lugar a figuras epistemológicas, a ciências, eventualmente a sistemas formalizados; o modo segundo o qual, em cada uma dessas formações discursivas, se situam e se realizam as passagens à epistemologização, à cientificidade, à formalização; a repartição desses limiares que podem coincidir, ser subordinados uns aos outros, ou estarem defasados no tempo; as relações laterais que podem existir entre figuras epistemológicas ou ciências, na medida em que se prendam a práticas discursivas vizinhas mais distintas" (p. 217).

Em síntese, o que está em questão é que a história arqueológica de Foucault não se ocupa da ciência em sua estrutura específica, mas sim, do domínio do saber, nos seus vários limiares.

\section{Foucault, a Psicologia e o Círculo de Epistemologia}

Foucault irá melhor esclarecer, a convite do Círculo de Epistemologia, o estatuto da ciência, sua história e seu conceito, esboçando, inclusive, questões fundamentais sobre tais temáticas, as quais irão se interarticular com o conteúdo do seu livro A Arqueologia do Saber - o qual acabamos de apresentar - e que foi publicado no ano seguinte a esse artigo. Desta forma, focalizaremos, agora, nossa atenção no artigo em questão.

No artigo publicado com o conteúdo desse debate, denominado Sobre a Arqueologia das Ciências - Resposta ao Círculo Epistemológico (1968/2005), Foucault, ao analisar o espaço epistêmico no qual as ciências se alojam, explica que, a partir de sua arqueologia, o que se busca é se desvencilhar de duas formas opostas e simétricas de extrapolação do campo do saber no qual uma ciência surge e se desenvolve.

Em um dos extremos dos saberes teríamos a matemática como exemplo de processo singular de formalização de extrapolação epistemológica, enquanto ciência que retoma "cada um dos episódios de sua evolução histórica no interior de seu sistema dedutivo" (Foucault, 1968/2005, p. 113), de maneira que se permita supor que "para uma ciência, bastam estas estruturas para definir a lei histórica de seu surgimento e desenvolvimento" (p. 113). Com isso, atribui-se à sequência teleológica de evoluções, inerentes ao interior dessa ciência, a condição de dar conta da sua historicidade, sem considerar os sistemas de dispersão dos saberes, formações e práticas discursivas que concorrem na sua constituição, muitas vezes indireta e exteriormente à dinâmica interna da matemática. Em sentido oposto e em outro extremo, temos a psicologia e a sociologia enquanto exemplos de extrapolação genética. Esse tipo de extrapolação é explicado ao considerar a forma psicológica enquanto discurso que se assegura como ciência "através do tempo pela narrativa ou pela retomada crítica de sua história" (Foucault, 1968/2005, p. 113).

Dessa maneira, essa extrapolação genética se configura considerando que a sociologia e a psicologia "situaram, a cada instante, seu discurso em um campo histórico que elas próprias percorriam através do modo crítico da confirmação ou da invalidação" dos próprios dizeres que esses saberes produziram no transcurso de sua História (p. 114).

Ou seja, a produção - no que nos interessa mais diretamente, dos discursos psicológicos - passa a ser considerada científica pelo mero fato de ser reconhecida aprioristicamente como tal, entre seus pares, por meio das questões que a evolução interna dos seus dizeres - temporal e criticamente - venham a suscitar.

Ora, para Foucault, é epistemicamente inconsistente e equivocada essa pressuposição dos saberes psis de que a mera narrativa dos seus casos - produzida na multiplicidade de seus vários ambientes de trabalho, tais como, clínicas, laboratórios, instituições -, se revestida de uma linguagem científica (muitas vezes apropriada da Medicina ou da Biologia), já legitimaria os discursos psicológicos enquanto dizeres de ciência.

E mesmo que esses dizeres psis sejam acompanhados da discussão das diferenças epistêmicas de suas diversas sub-áreas de saberes enquanto pretensa ciência - aliás, muitas vezes, tais discussões se desenvolvem por meio de uma linguagem solene e formalmente rigorosa -, eles induzem a um erro de constituição de um domínio científico, visto que os discursos psicológicos não preenchem os pressupostos dos limiares de cientificidade e de formalização, já apresentados e debatidos neste artigo.

Assim, a matemática não considera o campo de historicidade no qual as suas estruturas epistemológicas e de saberes emergem, centrando sua fundamentação epistêmica exclusivamente nessa sua história rigorosa. Dessa maneira, compreendemos que os resultados da matemática se apresentam como verdades universais a priori, faltando ao pesquisador apenas descobri-las, sem submetê-las à relatividade das forças históricas que a produziram, inerentes à evolução da sua própria discursividade.

Em sentido contrário a essa direção epistêmica da Matemática, concordamos com Foucault que o afastamento da psicologia, enquanto ciência humana, das normas exigidas na instauração da cientificidade de um saber a leva a se apoiar nas evoluções e mutações inerentes ao interior de suas va- 
riadas correntes, com suas alterações conceituais, mudanças de proposições nos seus sistemas de validade de enunciados, próprios a cada uma delas.

Ou seja, compreendemos que o que está em jogo é a sustentação da psicologia como ciência, não a partir de um rigor formal que, por si só (como é o caso da matemática), equivocadamente considera bastar para seu reconhecimento científico. Mas a psicologia surge enquanto conjunto de discursos sobre a psique humana que se legitimam ao se remeterem mutuamente aos contrapontos de suas próprias abordagens, mesmo que todas não preencham plenamente os pressupostos que se esperam de uma ciência. É uma ciência que se afirma na genealogia de sua própria história sem questionar os pressupostos discursivos que garantiriam o objeto de saber, a psique, como científico ou não.

Essa imprecisão epistêmica da psicologia, Foucault (1968/2005) denomina de ilusão formalizadora, inerente a uma doxologia que, na verdade, é a mera "descrição (sociológica ou linguística, estatística ou interpretativa) dos fatos de opinião" (p. 114) que, ao se apropriarem de métodos e discursos científicos, qualitativos e empíricos, se aparentam fazer ciência, mas do ponto de vista arqueológico, não o são. Para Foucault, é "ilusão supor que a ciência se enraíza na plenitude de uma experiência concreta e vivida" (p. 116), ou seja, a ilusão formalizadora da psicologia advém do fato de sustentar sua pretensa cientificidade na experiência das subdisciplinas que a constitui, o que não determina a transmutação do saber psicológico, como vimos, em ciência psicológica.

\section{Discussão}

Nosso estudo visa oferecer subsídios para a compreensão da constituição histórico-discursiva dos sujeitos e dos objetos psicológicos. Assim, vimos em A Ordem do Discurso que o acontecimento discursivo, em sua expressão difusa dos dizeres não incorporados ao interior de um determinado jogo de saber - seja ele científico ou pré-científico, psicológico ou de outra ordem de enunciação -, gera um campo de práticas discursivas tensas, no processo de transmutação do enunciado selvagem em verdade, fixada em determinado campo de saber.

Compreendemos, então, que embora a psicologia debata as questões da constituição de um sujeito psicológico periférico e transgressor - por exemplo, sobre as suas monstruosidades, anomalias, perversões, diferenças e múltiplos déficits -, tais questionamentos se situam no interior de um saber disciplinar, gerado para conter o caráter volátil do acontecimento discursivo, ainda não formatado pelos jogos anônimos de produção de verdades dos saberes científicos modernos.

Nesse contexto, vimos que em A Arqueologia do Saber, Foucault (1969/1997) nos sensibiliza para os vários patamares de conformação dos dizeres dispersos na sociedade, na produção de seus decorrentes campos de saberes, dentre eles, a psicologia.

Por sua vez, relevar que a historicidade dos saberes está afeita a jogos de verdades, com erros e acertos e, principalmente, incompletudes e descontinuidades, referentes à constante produção de espaços de tensões entre dizeres selvagens e disciplinados, nos abre a possibilidade de uma reflexão crítica sobre nossa posição nesses referidos jogos enquanto psicólogos, em nossos variados campos de atuação.

Sob este enfoque, constatamos que o pensamento foucaultiano nos sensibiliza sobre a diversidade dos arranjos discursivos da psicologia, a qual ilustramos, seja a partir de exemplos nossos ou dele, no estudo do caráter multifacetado de uma psicologia, não compreendida como um saber contínuo e totalizado. Ao contrário, uma psicologia vista a partir de um enfoque que evidencia a pluralidade dos jogos discursivos que constituem esse saber, desde os embates de sua epistemologização (que a diferencia do xamanismo ou da astrologia), passando por limiares multifacetados, os quais permitem a constituição de sua individualização, diversamente da medicina, da matemática ou qualquer outro saber historicamente produzido.

Nesse sentido, novamente nos reportamos ao artigo Resposta a Uma Questão, no qual Foucault (1968/1972) considera que uma epistemologia não deva ser considerada como "um estágio geral da razão" (p. 61), de forma a compor uma unidade de saber contínua, isolada e monolítica. Isso porque Foucault visa "colocar entre parênteses todas as velhas formas de continuidade fraca pelas quais se atenua geralmente o fato selvagem da mudança (tradição, influência, hábitos de pensamento, grandes formas mentais, sujeições do espírito humano)" (p. 61).

Assim, relacionando a psicologia a um campo de saberes múltiplos e descontínuos, proposto por Foucault (1968/1972), o que temos é uma epistemologia dos saberes em geral, em uma "relação complexa de decalagens sucessivas" (p. 61), constituída por discursos que se remetem tanto os saberes do senso comum, quanto aos pensamentos pré-científicos e científicos das mais diversas categorias de enunciados, os quais exemplificamos no transcurso deste nosso artigo.

Por sua vez, Foucault (1968/1972) intenciona "colocar entre parênteses todas as explicações psicológicas da mudança (gênio dos grandes inventores, crises da consciência, aparecimento de uma nova forma de espírito)" (p. 62). Com isso, simultaneamente critica e apresenta alternativa às concepções da psicologia que se apresentam a partir de uma perspectiva personalista de autor todo-poderoso, produtor individualizado das verdades da psique, o qual sobrepuja, a partir de seu eu encapsulado, as crises dos saberes psis no curso da história.

Ou seja, para Foucault, o enunciado da psicologia do sujeito não se aplica apenas à dinâmica interna dos saberes psicológicos enquanto estudos sobre o indivíduo, mas também enquanto pressuposição psicologizadora, referida ao processo de produção do próprio campo epistêmico da psicologia como um todo.

De maneira geral, em articulação à abordagem psicologizante de um eu soberano, produtor das verdades $p s i s$, Foucault (1968/1972) nos ensina que não podemos reduzir a produção dos saberes em geral ao tema de um "devir (forma geral, elemento abstrato, causa primeira e efeito universal, mistura confusa do idêntico e do novo) pela análise das transformações na sua especificidade" (p. 62).

Compreendemos que essa perspectiva, criticada por Foucault, pressupõe que o sujeito psicológico seja apreendido como espontânea emergência de uma história universal, 
contínua e linear do homem enquanto ser naturalizado, não submetido à história dos discursos, os quais, sob a ótica de Foucault, constituiriam nossos corpos e almas. Destacamos que estes, por sua vez, não seriam materialidades também naturais, estruturais e a-históricas, mas sim, visibilidades produzidas pelos discursos em geral, dentre eles, os saberes psis.

Em síntese, Foucault nos sensibiliza para uma arqueologia da psicologia que, ao tratar da individualização dos saberes psicológicos, pluraliza seu processo de constituição, seja na crítica a uma pressuposição de uma história contínua, unitária e totalizadora da psicologia; seja na desqualificação de uma história dos discursos fundada no papel autocentrado do sujeito cognoscente, no processo de produção do saber psicológico. Foucault nos leva a refletir, inclusive, sobre o desvelamento dos fundamentos dos saberes psicológicos que naturalizam nossos corpos e almas, isentando-os dos embates produtores dos discursos na história.

Por sua vez, o conjunto geral de todas essas reflexões acima citadas nos lança não só à revisão da dinâmica interna dos saberes da Psicologia propriamente considerados, mas nos leva à problematização de uma gama multifacetada de jogos de verdades que os atravessa, na dinâmica dos múltiplos campos de saberes - concorrentes, paralelos, tangentes - que compõem o amplo relevo dos discursos de determinado momento da História, no qual os saberes psicológicos possam ser situados

Como efeito, evidenciamos o apagamento dos contornos, tanto do campo discursivo da psicologia, como também da miríade dos demais saberes e discursos, no transcurso, não apenas da história da psicologia, mas do pensamento humano, em seus anônimos e móveis jogos de verdades - dramáticos, descontínuos e plurais -, selvagens ou disciplinados.

\section{Referências}

Dreyfus, H., \& Rabinow, P. (1995). Michel Foucault: uma trajetória filosófica (V. P. Carrero, Trad.). Rio de Janeiro: Forense Universitária. (Trabalho original publicado em 1984)

Foucault, M. (1972). Resposta a uma questão. Tempo Brasileiro, 28, 57-81 (M. G. R. Silva, Trad.). (Trabalho original publicado em 1968)

Foucault, M. (1994). História da loucura (J. T. C. Netto, Trad.). São Paulo: Perspectiva. (Trabalho original publicado em 1961)

Foucault, M. (1995). As palavras e as coisas (S. T. Muchail, Trad.). São Paulo: Martins Fontes. (Trabalho original publicado em 1966)

Foucault, M. (1996). A ordem do discurso (L. F. A. Sampaio, Trad.). São Paulo: Loyola. (Trabalho original publicado em 1971)

Foucault, M. (1997). A arqueologia do saber (L. F. B. Neves, Trad.). Rio de Janeiro: Forense Universitária. (Trabalho original publicado em 1969)

Foucault, M. (2005). Sobre a arqueologia das ciências - Resposta ao círculo epistemológico. Em M. B. Motta (Org.), Arqueologia das ciências e história dos sistemas de pensamento - Michel Foucault (V. L. A. Ribeiro, Trad.) (pp. 82-117). Rio de Janeiro: Forense Universitária. (Trabalho original publicado em 1968)

Monzani, L. R. (1989). Freud: o movimento de um pensamento. Campinas: Unicamp.

\author{
Recebido em 20.11.08 \\ Primeira decisão editorial em 28.09.09 \\ Versão final em 10.09.10 \\ Aceito em 10.09.10
}

